\title{
A first generation BAC-based physical map of the half-smooth tongue sole (Cynoglossus semilaevis) genome
}

\author{
Junjie Zhang ${ }^{1,2,3}$, Changwei Shao', Liyan Zhang ${ }^{1}$, Kun Liu', Fengtao Gao ${ }^{1}$, Zhongdian Dong ${ }^{1}$, Peng Xu ${ }^{4 *}$ \\ and Songlin Chen ${ }^{1 *}$
}

\begin{abstract}
Background: Half-smooth tongue sole (Cynoglossus semilaevis Günther) has been exploited as a commercially important cultured marine flatfish, and female grows 2-3 times faster than male. Genetic studies, especially on the chromosomal sex-determining system of this species, have been carried out in the last decade. Although the genome of half-smooth tongue sole was relatively small $(626.9 \mathrm{Mb})$, there are still some difficulties in the high-quality assembly of the next generation genome sequencing reads without the assistance of a physical map, especially for the $W$ chromosome of this fish due to abundance of repetitive sequences. The objective of this study is to construct a bacterial artificial chromosome (BAC)-based physical map for half-smooth tongue sole with the method of high information content fingerprinting (HICF).
\end{abstract}

Results: A physical map of half-smooth tongue sole was constructed with 30, 294 valid fingerprints $(7.5 \times$ genome coverage) with a tolerance of 4 and an initial cutoff of 1e-60. A total of 29,709 clones were assembled into 1,485 contigs with an average length of $539 \mathrm{~kb}$ and a N50 length of $664 \mathrm{~kb}$. There were 394 contigs longer than the N50 length, and these contigs will be a useful resource for future integration with linkage map and whole genome sequence assembly. The estimated physical length of the assembled contigs was $797 \mathrm{Mb}$, representing approximately 1.27 coverage of the half-smooth tongue sole genome. The largest contig contained 410 BAC clones with a physical length of $3.48 \mathrm{Mb}$. Almost all of the 676 BAC clones (99.9\%) in the 21 randomly selected contigs were positively validated by PCR assays, thereby confirming the reliability of the assembly.

Conclusions: A first generation BAC-based physical map of half-smooth tongue sole was constructed with high reliability. The map will promote genetic improvement programs of this fish, especially integration of physical and genetic maps, fine-mappings of important gene and/or QTL, comparative and evolutionary genomics studies, as well as whole genome sequence assembly.

Keywords: Half-smooth tongue sole, Cynoglossus semilaevis, BAC library, Physical map, Genome

\section{Background}

Half-smooth tongue sole (Cynoglossus semilaevis Günther) is a marine flatfish that belongs to the family Cynoglossidae in the order Pleuronectiformes, and is widely distributed in Chinese coastal water [1,2]. Because of its rarity and delicacy, half-smooth tongue sole has been

\footnotetext{
*Correspondence: chensl@ysfri.ac.cn; xupeng@cafs.ac.cn

'Yellow Sea Fisheries Research Institute, Chinese Academy of Fishery

Sciences, Qingdao 266071, China

${ }^{4}$ The Centre for Applied Aquatic Genomics, Chinese Academy of Fishery

Sciences, Beijing 100141, China

Full list of author information is available at the end of the article
}

exploited as a commercially important cultured marine fish, especially in the Shandong Peninsula [3]. Because female grows 2-3 times faster than male, the development of all-female stocks of this fish would be of significant benefit for aquaculture and this fish could be an ideal model for the study on sex-determination mechanisms in teleosts [4]. Genetic studies, especially on the sex-determining mechanism of this species, have been carried out in the last decade. The chromosomal sexdetermining mechanism in half-smooth tongue sole was determined to be female heterogametic with the $\mathrm{ZW}$ 
chromosomes [5-7]. A large number of genetic markers [8-10], especially female-specific amplified fragment length polymorphism (AFLP) markers have been developed [4] and a large number of ESTs have been analyzed [11]. Recently significant progress on the development of gynogenetic stocks [6] and characterization of sexrelated genes [12-14] has been made.

Half-smooth tongue sole has a relatively small genome of about $626.9 \mathrm{Mb}$ as estimated by flow cytometry [15]. To study the genomics of half-smooth tongue sole, two bacterial artificial chromosome (BAC) libraries with an average insert size of $156 \mathrm{~kb}$ have been constructed previously [15]. Meanwhile, microsatellite-based genetic linkage maps with different densities have been constructed, and four quantitative trait loci (QTLs) related to growth rate, seven sex-related loci and five sex-related markers have been located on the relevant chromosomes $[16,17]$. These studies have laid the foundation for the future genetic improvement of half-smooth tongue sole. However, no genome-wide physical map has been constructed for halfsmooth tongue sole to date, and there are still some difficulties in high-quality assembly of the next generation genome sequencing reads without assistance of a physical map, especially for the $\mathrm{W}$ chromosome of this fish due to abundance of repetitive sequences $[18,19]$.

A physical map of a species is the starting point of the clone-by-clone genome sequencing approach [20] and always constructed as a series of linear orderings of clones in a genomic library using their overlapping. Map-based sequencing strategies are expensive and laborious and, as a result, they have partly been replaced by shotgun sequencing strategies [21]. However, abundance of repetitive sequences, large gene families and extensive segmental duplications always complicate the assembly of whole-genome shotgun reads obtained from next generation sequencing platforms, and only physical maps can deal with these problems [22,23]. Moreover, a genome-wide physical map is also one of the foundations for integration of physical, genetic and cytogenetic maps, and could be used to fine-map economically important genes and/or QTLs and evolutionary genomics studies [24-30]. The economically important genes and/ or QTLs and genome sequence information of a species in agriculture are important foundations of markerassisted selection breeding and whole genome selection breeding. Therefore, the construction of a physical map of the half-smooth tongue sole genome has become essential to complete the final whole-genome sequence assembly as well as to accelerate the progress in genetic improvement programs of this fish.

Several fingerprinting methods with BAC libraries had been developed, such as agarose gel electrophoresis, DNA sequencing electrophoresis and high information content fingerprinting ( $\mathrm{HICF}$ ) with $\mathrm{SNaPshot} \mathrm{labeling}$ kit [31-33]. Each of them had been used to construct physical map for some species. For example, the physical map of human genome was constructed with the method of agarose gel electrophoresis [34], the physical map of soybean genome was constructed with the method of DNA sequencing electrophoresis [35], and the physical maps of wheat and Brassica rapa genomes were constructed using the method of HICF with SNaPshot labeling kit $[29,36]$. Now genome physical maps for a number of aquatic species have been also constructed with these different methods. For example, physical maps of threespine sticklebacks (Gasterosteus aculeatus) and Atlantic salmon (Salmo salar) were constructed with the method of agarose gel electrophoresis [37,38], physical maps of Nile tilapia (Oreochromis niloticus) and Zhikong Scallop (Chlamys farreri) were constructed with the method of DNA sequencing electrophoresis $[39,40]$, while the method of HICF with SNaPshot labeling kit has been used to construct physical maps for channel catfish (Ictalurus punctatus), rainbow trout (Oncorhynchus mykiss), Asian seabass (Lates calcarifer) and common carp (Cyprinus carpio) [41-45].

Here we report a first generation BAC-based physical map of the half-smooth tongue sole genome constructed with the method of HICF and the FingerPrinted Contig (FPC) program v9.4 [46].

\section{Results and discussion}

\section{$B A C$ fingerprinting and data processing}

The HICF method was chosen to develop a physical map of half-smooth tongue sole due to its wellestablished format with the commercially available SNaPshot kit (Life Technologies, Foster City, CA, USA) and its high throughput by using the ABI 3730xl sequencer (Life Technologies) [33,36,44,45,47]. A total of 33,575 clones (approximately 8.3-fold genome coverage) mainly from the HindIII BAC library were fingerprinted after digestion with a combination of five restriction enzymes. Of these fingerprints, 3,281 (9.8\%) were removed by FPminer 2.1 (Bioinforsoft LLC, Beaverton, OR, USA) due to low quality. The remaining 30,294 valid clones (90.2\%) represented approximately 7.5-fold coverage of the half-smooth tongue sole genome. The abundance distribution of the restriction bands in all these BAC fingerprints is presented in Figure 1. On average, each BAC clone contained 80.2 restriction bands, and about $60 \%$ of the valid clones contained proper numbers of restriction bands ranging from 60 to 100, and each band represented approximate $1.933 \mathrm{~kb}$ of BAC DNA fragment, as assessed from the average insert size $(155 \mathrm{~kb})$ of the HindIII BAC library [15].

\section{Determination of tolerance and cutoff}

Tolerance and cutoff are two important parameters used in the FPC program for contig assembly. Tolerance determines 


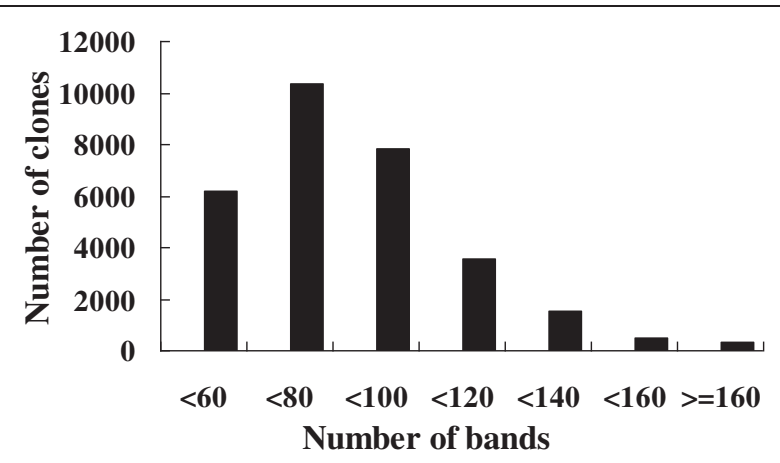

Figure 1 The abundance distribution of restriction bands in BAC clones of half-smooth tongue sole (Cynoglossus semilaevis). About $60 \%$ of the valid clones contained proper numbers of restriction bands ranging from 60 to 100 bands, and on average, one BAC clone contained 80.2 restriction bands.

how closely two bands in different clones need to match to be considered as the same band. Its value could be set according to the observed size variations of particular bands in the project $[42,44,48]$, and the size distributions of the two vector pECBAC1 fragments (157.4 bp and $369.6 \mathrm{bp}$ ) were analyzed (Figure 2). The standard deviations of them in 300 randomly selected clones were $0.085 \mathrm{bp}$ and $0.062 \mathrm{bp}$, and the sizes of the $95 \%$ confidence intervals were $0.334 \mathrm{bp}$ and $0.243 \mathrm{bp}$ (Table 1). Because the FPC program does not allow the use of decimals and all fragment sizes were multiplied by 10 , the tolerance value was set at 4 , corresponding to $0.4 \mathrm{bp}$ of primary fingerprint size. This value was first determined for SNaPshot-HICF by Luo et al. [33] and was used in construction of physical maps for several aquatic species $[42,44,45]$.

Cutoff is a threshold of the probability that fingerprint bands of two clones match by coincidence. Lowering cutoff value could increase the stringency of contig assembly and decrease the probability of chimeric joining of duplicated or repetitive regions $[42,44,45]$. However, if cutoff value is set too low, some real BAC contigs will be split into small contigs or singletons. A series of preliminary tests were performed on the whole data with different cutoff values ranging from $1 \mathrm{e}-20$ to $1 \mathrm{e}-75$, and the observed changes in the numbers of questionable clones ( $\mathrm{Q}$ clones), singletons, and contigs versus different cutoff values are presented in Additional file 1 . Along with the decrease of cutoff value from 1e-20 to $1 \mathrm{e}-75$, the number of singletons increased from 587 to 16259, the number of Q clones decreased from 12790 to 9 . When cutoff value was $1 \mathrm{e}-60$, the number of singletons was $8662(28.6 \%)$ and the number of Q clones was 234 (1.1\%). According to the method of Brassica rapa physical map assembly, the fraction of clones assembled (71.4\%) was sufficient to give a robust basis for the further assemblies [36]. The very low fraction of $Q$ clones shown that initial assembly with the cutoff value of $1 \mathrm{e}-60$ was reliable. So a cutoff value of $1 \mathrm{e}-60$ was reasonably stringent and chosen for the initial assembly.

\section{Contig assembly}

The physical map contigs of half-smooth tongue sole were assembled using the FPC v9.4 program with a tolerance of 4 and an initial cutoff value of 1e-60 in three steps (Table 2). First, 4,200 contigs were constructed with 21,632 clones and $234 \mathrm{Q}$ clones distributed in 145 Q contigs were produced in initial assembly. Then 39 Q contigs with more than $10 \%$ Q clones were broken up by "DQer" function. Finally, 2,715 contigs were endmerged by "End to End" function, and 8,077 singletons were added to the end of contigs by "keyset to FPC" function at nine successively higher cutoffs from 1e-60 to $1 \mathrm{e}-15$. The average contig length was increased from $233 \mathrm{~kb}$ to $539 \mathrm{~kb}$, and the length of the largest contig was increased from $958 \mathrm{~kb}$ to $3,481 \mathrm{~kb}$, while the physical length of the total contigs was decreased from $980 \mathrm{Mb}$ to $797 \mathrm{Mb}$, and the genome coverage was also decreased from 1.56 to 1.27. These changes suggested that the "End to End" and "keyset to FPC" functions of the FPC program obviously improved the quality of the contig assembly. The final physical map had 1,485 contigs assembled with a total of 29,709 BAC clones; 585 clones remained as singletons. A summary of the halfsmooth tongue sole physical map data is presented in Table 3.

\section{Genome coverage}

Based on the average insert size $(155 \mathrm{~kb})$ of the BAC library [15], the valid 30,294 clones summed up a total of 3,455.97 Mb, which represented 7.5-fold coverage of the haploid genome of half-smooth tongue sole. Though this coverage is smaller than the coverage reported for Atlantic salmon $(11.5 \times)$ and rainbow trout $(8.3 \times)$ [38,43], it is larger than the coverage obtained for Nile tilapia (5.6x), channel catfish (5.6x), Asian seabass (4.9x), common carp $(5.9 \times)$ and Zhikong scallop (5.8×) [39,40,42,44,45]. Therefore, the 30,294 valid clones obtained here should be sufficient to construct a practicable and reliable BACbased physical map of half-smooth tongue sole.

There were a total of 412,292 consensus bands in the final version of contig assembly, representing approximate $797 \mathrm{Mb}$ of genome physical length $(412,292 \times$ $1.933 \mathrm{~kb}$ per consensus band). On average, each BAC clone contributed 13.9 distinct bands or $26.8 \mathrm{~kb}$ linear length to the assembly. The estimated physical length was slightly longer than the size of half-smooth tongue sole genome estimated by the flow cytometry method $(626.9 \mathrm{Mb})$ [15], and was about $1.27 \times$ genome coverage. The longer genome coverage might be due to the overestimation of the average insert size of the BAC library, or the heterogeneity of BAC DNA from three female 

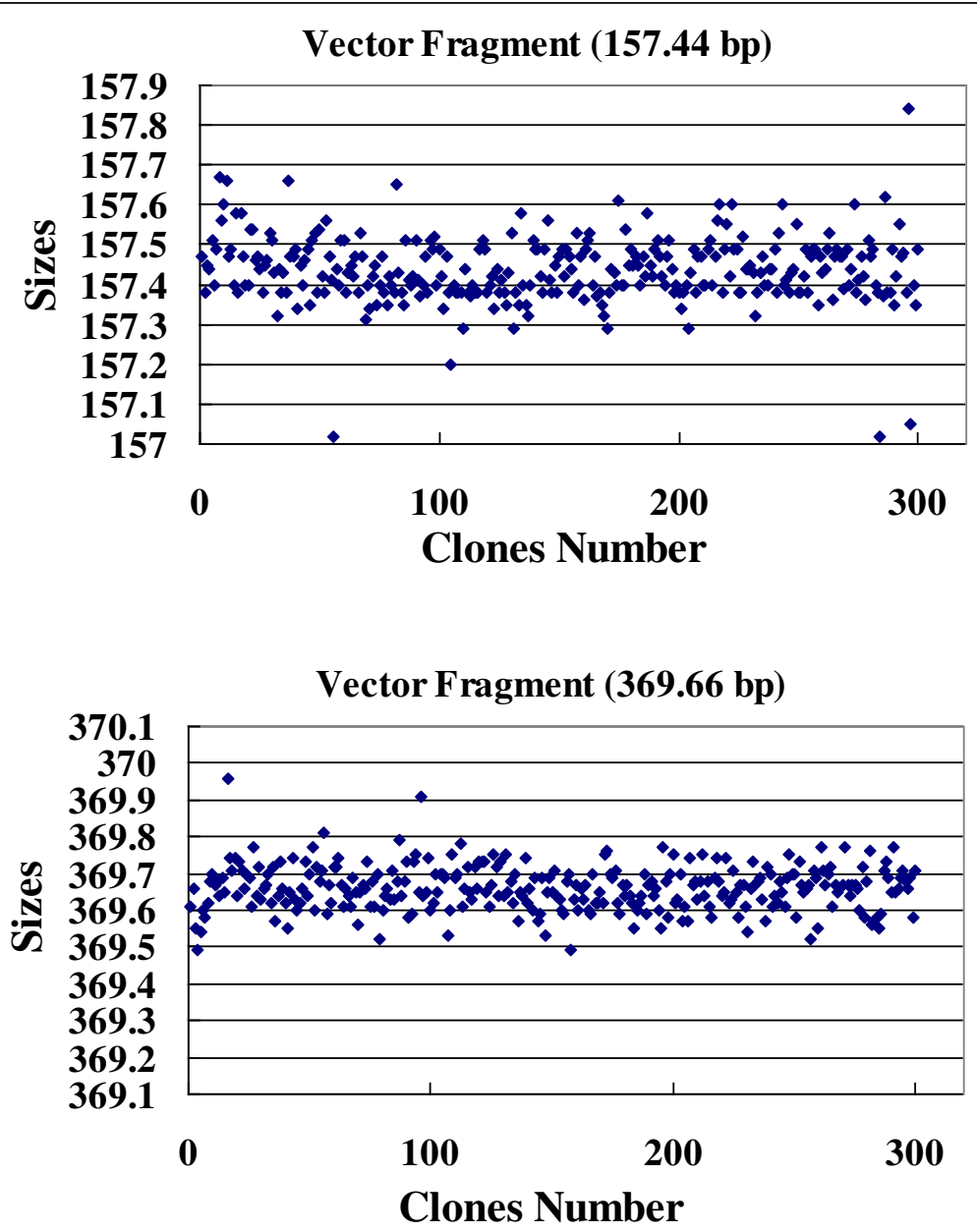

Figure $\mathbf{2}$ The size distributions of two vector fragments in $\mathbf{3 0 0}$ randomly selected fingerprinting samples. According to the $95 \%$ confidence intervals of the two vector fragments ( $157.4 \mathrm{bp}$ and $369.6 \mathrm{bp})$, a tolerance of 4 was set for automatic contig assembly with program FPC, corresponding to 0.4 bp of primary fingerprint size.

half-smooth tongue sole fishes. Similar results were reported for the physical maps of other species such as Nile tilapia $(1.65 \times)$, Zhikong scallop $(1.5 \times)$ and turnip $(1.3 \times)[36,39,40]$. This result also implied that the resultant contigs did not sufficiently overlap with each other and the gaps between the contigs might be closed by additional BAC fingerprints or additional rounds of endmerging at lower stringency [49]. Lower stringency, however, would likely decrease the reliability of the resultant physical contigs and should be performed by manual editing with the assistance of markers.

Table 1 The standard deviations and $95 \%$ confidence intervals of two vector fragments in random 300 clones

\begin{tabular}{lllll}
\hline $\begin{array}{l}\text { Vector } \\
\text { fragments }\end{array}$ & $\begin{array}{l}\text { Sample } \\
\text { number }\end{array}$ & $\begin{array}{l}\text { Standard } \\
\text { deviation }\end{array}$ & $\begin{array}{l}\text { 95\% confidence } \\
\text { interval }\end{array}$ & $\begin{array}{l}\text { Interval } \\
\text { size }\end{array}$ \\
\hline $157.44 \mathrm{bp}$ & 300 & $0.085 \mathrm{bp}$ & $157.271-157.604 \mathrm{bp}$ & $0.334 \mathrm{bp}$ \\
$369.66 \mathrm{bp}$ & 300 & $0.062 \mathrm{bp}$ & $369.540-369.782 \mathrm{bp}$ & $0.243 \mathrm{bp}$ \\
\hline
\end{tabular}

\section{$Q$ clones and $Q$ contigs}

If a clone contains more than 50\% extra bands, which do not actually align to the map, it would be labeled as a Q clone even when it is correctly located on the consensus map [46]. Q clones are generated by inconsistency in enzyme digestion, cross-contamination, abundance of repetitive sequences, and/or extensive segmental duplication, even genome duplication, and its existence could result in a false positive overlap with another clone and even with another contig. Q contigs, especially those with more than $10 \%$ Q clones, are usually broken into two or more contigs to prevent or decrease the chance of chimeric joining. In this study, the initial contig assembly with a cutoff value of $1 \mathrm{e}-60$ produced only $41 \mathrm{Q}$ contigs having more than $10 \%$ Q clones. The "DQer" function was performed by decreasing the cutoff value as low as 1 e- 87 where necessary and broke up $37 \mathrm{Q}$ contigs with more than 10\% Q clones. Although the numbers of contigs and 
Table 2 The building process of half-smooth tongue sole physical map with 30,294 BAC clones

\begin{tabular}{|c|c|c|c|c|c|c|c|c|c|c|c|c|c|}
\hline \multirow[t]{2}{*}{ Assembly Steps } & \multirow[t]{2}{*}{ Contigs } & \multirow[t]{2}{*}{ Singletons } & \multirow{2}{*}{$\begin{array}{l}\text { Physical } \\
\text { length(Mb) }\end{array}$} & \multirow{2}{*}{$\begin{array}{l}\text { Genome } \\
\text { coverage }\end{array}$} & \multirow{2}{*}{$\begin{array}{l}\text { Q-contigs/ } \\
\text { Q-clones }\end{array}$} & \multirow{2}{*}{$\begin{array}{l}\text { Longest } \\
\text { contig(kb) }\end{array}$} & \multirow{2}{*}{$\begin{array}{l}\text { Avr. contig } \\
\text { length }(k b)\end{array}$} & \multicolumn{6}{|c|}{ NO. of contigs in different sizes } \\
\hline & & & & & & & & $\geq 100$ & $99-50$ & $49-25$ & $24-10$ & $9-3$ & $=2$ \\
\hline Initial 1e-60 & 4200 & 8662 & 980 & 1.56 & $145 / 234$ & 958 & 233 & 0 & 1 & 28 & 493 & 2312 & 1366 \\
\hline DQer (1e-60 to 1e-87) & 4260 & 8807 & 989 & 1.58 & $106 / 133$ & 958 & 232 & 0 & 0 & 27 & 476 & 2365 & 1392 \\
\hline Merge 1e-55, 1 & 3792 & 7445 & 960 & 1.53 & $106 / 133$ & 1030 & 253 & 0 & 3 & 40 & 604 & 2252 & 893 \\
\hline Merge 1e-45, 1 & 2845 & 5219 & 894 & 1.43 & $105 / 133$ & 1465 & 314 & 1 & 7 & 140 & 742 & 1598 & 357 \\
\hline Merge 1e-35, 2 & 2592 & 3356 & 879 & 1.40 & 103/133 & 1465 & 339 & 1 & 11 & 198 & 779 & 1355 & 248 \\
\hline Merge 1e-25, 2 & 2022 & 1759 & 838 & 1.34 & $102 / 133$ & 2221 & 414 & 4 & 46 & 267 & 735 & 844 & 126 \\
\hline Merge 1e-15, 2 & 1485 & 585 & 797 & 1.27 & $101 / 133$ & 3481 & 539 & 9 & 83 & 311 & 598 & 427 & 57 \\
\hline
\end{tabular}

Note: Contig assembly was performed with the tolerance of 4 and the initial cutoff value of 1e-60, followed by iteration of the end-merge, and singleton-merge routines by means of FPC v9.4. Additional end-merge and singleton-merge routines at 1e-40, $1 \mathrm{e}-30$ and $1 \mathrm{e}-20$ are not shown.

singletons increased, the reliability of the resultant contigs should be greatly improved.

In the final version of assembly, there remained a total of $133 \mathrm{Q}$ clones distributing in $101 \mathrm{Q}$ contigs, corresponding to $0.45 \%$ of the clones assembled in the physical map. This fraction is much less than the fractions of $\mathrm{Q}$ clones reported in the physical maps of other species such as channel catfish $(4.3 \%$ and $7.3 \%)$, rainbow trout (1.4\%), Asian sea bass (4.6\%), common carp (2.1\%), maize (11\%) and turnip (15\%) $[36,41-45,49]$. The fraction of Q contigs (6.8\%) was also lower than the fraction reported in the maps of other species such as Nile tilapia (24.3\%), channel catfish (15.6\%), rainbow trout (19.4\%) and common carp $(23.9 \%)[39,42,43,45]$. These fractions implied that the chance of false positive overlap in our assembly was substantially lower than these species.

Nelson et al. [49] demonstrated that most increase of the number of $\mathrm{Q}$ clones in a map mainly came from the

\section{Table 3 Statistics of the first generation BAC-based} physical map of half-smooth tongue sole genome

\begin{tabular}{lll}
\hline Number of BAC clones fingerprinted & 33,575 & $\sim 8.3 \times$ genome coverage \\
Valid fingerprints for FPC assembly & 30,294 & $\sim 7.5 \times$ genome coverage \\
Total number of contigs assembled & 1,485 & \\
Clones contained in the 1,485 contigs & 29,709 & $\sim 7.3 \times$ genome coverage \\
Average number of clones per contig & 20 & \\
Average contig size in consensus bands (CB) & 278 & \\
Estimated average contig size (kb) & 539 & \\
Longest contig (ctg31; kb) & 3,481 & \\
Estimated N50 contig size (kb) & 664 & \\
Number of Q-contigs & 101 & $6.8 \%$ \\
Number of Q-clones & 133 & $0.45 \%$ \\
Number of singletons & 585 & $1.93 \%$ \\
Average insert size of the BAC library (kb) & 155 & \\
Bands number of per BAC clone & 80.2 & \\
Average size each band represents (kb) & 1.933 \\
Total number of bands included in the contigs & 412,292 \\
Total physical length of assembled contigs (kb) & 796,960 & $\sim 1.27 \times$ genome coverage \\
\hline
\end{tabular}

adding of singletons into the ends of contigs. However, in our study, the number of $\mathrm{Q}$ clones did not increase along with the integration of the 8,077 singletons into the ends of contigs and remained invariable at the very low level of 133. This finding also suggested that the most of singletons merged in the end of the contigs were from the regions of low coverage.

\section{Size distribution of contigs}

With the increase of cutoff value from 1e-60 to 1e-15, the average size of the contigs was also increased (Table 2). The final size distribution of contigs in the physical map of the half-smooth tongue sole genome is shown in Figure 3. Overall, most of the contigs (96.2\%) contained more than two BAC clones, $67.4 \%$ contained more than nine clones, and $27.1 \%$ contained more than 24 clones. On average, one contig in the final assembly contained 20 BAC clones. The largest contig (ctg31) contained 410 BAC clones and had a physical length of $3.48 \mathrm{Mb}$. The N50 length of the final assembly was $664 \mathrm{~kb}$ and there were 394 contigs longer than it. These contigs would be a useful resource for the future

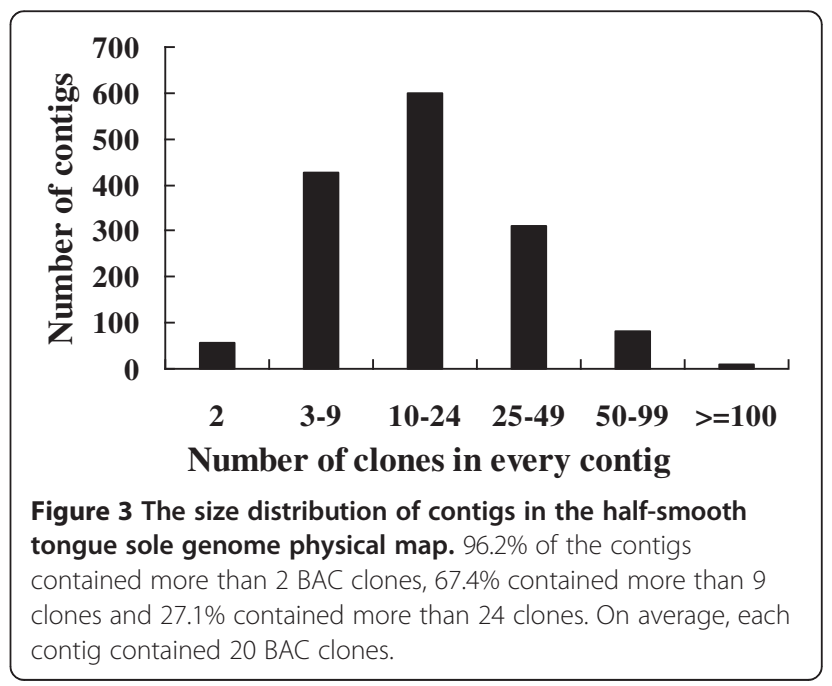


integration with linkage map and whole genome sequence assembly.

\section{Assessment of the physical map}

The half-smooth tongue sole physical map assembly was judged to be reliable preliminarily based on enough genome coverage of valid clones, the very low cutoff value, and the very low fractions of $\mathrm{Q}$ clones and $\mathrm{Q}$ contigs. PCR assays of randomly selected contigs were used to further assess the reliability of the physical map assembly. If all clones of a contig truly overlap and belong to the contig, they should be identified by PCR amplification with proper primer pairs, thereby validating the contig [45]. Twenty-one contigs of various lengths (307-1276 kb) were randomly selected with consideration of the distribution of the clones end-sequenced. The average length and clone numbers of these contigs were $530 \mathrm{~kb}$ and 32, respectively. For short contigs, PCR reactions were performed on all clones of each contig, while for long contigs, reactions were conducted on some near the clones developing primers.

The results of the PCR assays of 21 contigs are shown in Table 4. All clones of 20 contigs were positively

\begin{tabular}{|c|c|c|c|c|c|}
\hline Contig ID & $\begin{array}{l}\text { Physical } \\
\text { lengths } \\
\text { (kb) }\end{array}$ & $\begin{array}{l}\text { Number } \\
\text { of clones }\end{array}$ & $\begin{array}{l}\text { Number } \\
\text { of positive } \\
\text { clones }\end{array}$ & $\begin{array}{l}\text { Proportion } \\
\text { of positive } \\
\text { clones }\end{array}$ & $\begin{array}{l}\text { Number } \\
\text { of primer } \\
\text { pairs }\end{array}$ \\
\hline 724 & 360 & 18 & 18 & $100 \%$ & 3 \\
\hline 2,113 & 383 & 17 & 17 & $100 \%$ & 3 \\
\hline 27 & 309 & 16 & 16 & $100 \%$ & 2 \\
\hline 2,259 & 307 & 13 & 13 & $100 \%$ & 2 \\
\hline 9 & 499 & 28 & 28 & $100 \%$ & 2 \\
\hline 17 & 410 & 19 & 19 & $100 \%$ & 2 \\
\hline 85 & 479 & 20 & 20 & $100 \%$ & 2 \\
\hline 122 & 352 & 21 & 21 & $100 \%$ & 2 \\
\hline 195 & 501 & 42 & 42 & $100 \%$ & 3 \\
\hline 148 & 431 & 16 & 16 & $100 \%$ & 2 \\
\hline 172 & 397 & 34 & 34 & $100 \%$ & 2 \\
\hline 14 & 396 & 43 & 43 & $100 \%$ & 4 \\
\hline 1,458 & 462 & 27 & 27 & $100 \%$ & 3 \\
\hline 52 & 617 & 34 & 34 & $100 \%$ & 3 \\
\hline 175 & 704 & 51 & 51 & $100 \%$ & 2 \\
\hline 996 & 329 & 43 & 43 & $100 \%$ & 1 \\
\hline 252 & 503 & 26 & 26 & $100 \%$ & 4 \\
\hline 143 & 941 & 63 & 62 & $98.4 \%$ & 7 \\
\hline 113 & 1,276 & 76 & 76 & $100 \%$ & 9 \\
\hline 451 & 1,135 & 52 & 52 & $100 \%$ & 5 \\
\hline 26 & 360 & 17 & 17 & $100 \%$ & 2 \\
\hline Total & 11,128 & 676 & 675 & $99.9 \%$ & 65 \\
\hline Average & $\sim 530$ & $\sim 32$ & $\sim 32$ & & $\sim 3$ \\
\hline
\end{tabular}

identified by the PCR assays with one or multiple pairs of primers, respectively, and an example (ctg 451) is shown in Figure 4. Fifty-two clones were included in the contig, and five pairs of PCR primers were developed from the end sequences of five clones (080D16, 070D11, 062I06, 080 F19, 074 M11). All clones near each of these five clones were positively amplified, respectively, and finally all of the 52 clones were positively identified. But in ctg143, one clone (141009) could not be positively identified by this way. This negative result might arise from either the lack of proper primers or possible chimeric overlapping during the assembly process. Overall, 675 of the $676 \mathrm{BAC}$ clones (99.9\%) in the 21 contigs were positively validated, confirming the high accuracy and reliability of the assembly.

\section{Conclusion}

A first generation BAC-based physical map of the halfsmooth tongue sole genome was constructed with 30 , 294 valid fingerprints $(7.5 \times$ genome coverage) using the method of HICF with SNaPshot kit and the FPC program v9.4. A total of 29,709 BAC clones were assembled into 1,485 contigs with an average length of $537 \mathrm{~kb}$ and a N50 length of $664 \mathrm{~kb}$. The physical length of the assembled map was $797 \mathrm{Mb}$. The reliability of the map assembly was validated by PCR assays on randomly selected 21 contigs. This physical map will promote the assembly of $\mathrm{W}$ chromosome and genetic improvement of half-smooth tongue sole.

\section{Methods}

Ethics Statement

All the experimental procedures involved in this study were approved by the Yellow Sea Fisheries Research Institute's animal care and use committee, and followed the experimental basic principles.

\section{Source of the BAC library}

Two BAC libraries, in the BamHI and HindIII sites of the vector $\mathrm{pECBAC1}$, were developed previously from three female half-smooth tongue sole fishes in our laboratory. The two libraries were arrayed in 144 384-well microtiter plates and consisted of a total of 55,296 BAC clones with an average insert size of $156 \mathrm{~kb}$, representing 13.4-fold coverage of the haploid genome [15]. Nearly all the BAC clones used for fingerprinting in this study were from the HindIII library with an average insert size of $155 \mathrm{~kb}$. A few of the BAC clones were from the BamHI library.

\section{BAC DNA isolation and fingerprinting}

To decrease the differences in BAC DNA yields, the BAC clones were inoculated and precultivated in new 384-well plates containing $60 \mu \mathrm{l}$ of $2 \times$ YT medium plus $12.5 \mu \mathrm{g} / \mathrm{ml}$ chloramphenicol using a 384-pin replicator 


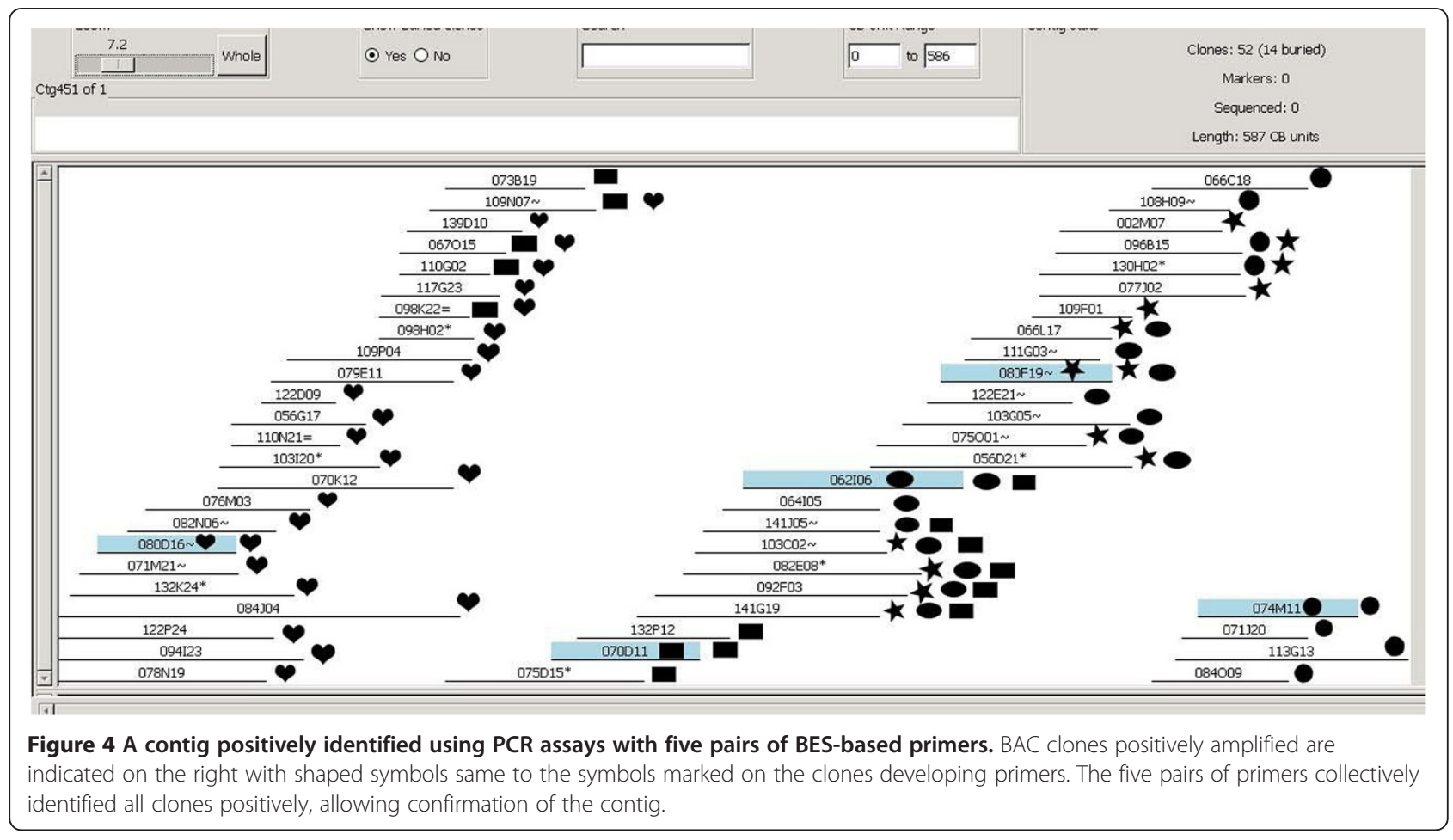

(BOEKEL, Feasterville, PA, USA). Plates were covered with adhesive air permeable seals (Excel Scientific, Victorville, CA, USA) and incubated at $37^{\circ} \mathrm{C}$ for $21-22 \mathrm{~h}$ with shaking at $300 \mathrm{rpm}$. Then the precultivated BAC clones from each 384-well plate were inoculated into four 96 deep-well plates using a 96-pin replicator (BOEKEL, Feasterville, PA, USA). Each well contained $1.4 \mathrm{ml}$ of $2 \times \mathrm{YT}$ medium plus $12.5 \mathrm{mg} / \mathrm{ml}$ chloramphenicol. The 96-well plates were covered and incubated at $37^{\circ} \mathrm{C}$ for $24-26 \mathrm{~h}$ with shaking at $300 \mathrm{rpm}$. BAC DNA was isolated using a modified alkaline lysis method followed by purification with $70 \%$ ethanol [50]. Dried BAC DNA was resuspended

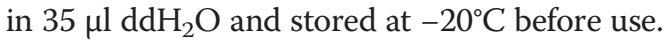

BAC DNA fingerprinting was performed according the method of Luo et al. [33]. The DNA of each clone was digested with a mixture of five restriction endonucleases, BamHI, EcoRI, XbaI, XhoI, and HaeIII (New England Biolabs, Ipswich, MA, USA) at $37^{\circ} \mathrm{C}$ for four hours. Fragments were end-labeled with the SNaPshot kit at $65^{\circ} \mathrm{C}$ for 60 minutes. The labeled BAC fragments were precipitated with sodium acetate and pre-chilled 100\% ethanol following by washing with $70 \%$ ethanol. Dried DNA fragments were resuspended in $10 \mu \mathrm{l}$ of $\mathrm{Hi}-\mathrm{Di}$ formamide plus $0.05 \mu \mathrm{l}$ GeneScan-500 LIZ as an internal size standard, denatured for $5 \mathrm{~min}$ at $95^{\circ} \mathrm{C}$, and analyzed on a 3730xl DNA Analyzer (Life Technologies).

\section{Fingerprint collection and processing}

The fragment sizes of all BAC clones were collected by the Data Collection program on the ABI 3730XL Genetic
Analyzer, and then processed with FPminer 2.1 software. Briefly, the threshold in peak finding was set as 35 relative fluorescent units (RFU), and the size range was set as 50500 bp. Fragments with a peak height greater than 6,000 RFU or with width greater than 15 were removed. Automatic fingerprinting editing was used to remove the potential background, and $70 \%$ was set as the cutoff percentage for the blue channel, while $75 \%$ was set for the other three color channels. The average highest peak in every color channel was counted from the top 3rd to the 7th peaks. After a cross-contamination check, potential contaminated clones with similarity coefficients greater than 0.25 were removed. All samples with a Size Standard Matching Quality Score below 0.9 or with a Fingerprint Editing Quality Score below 10 were also removed. In addition, vector and potential repetitive DNA fragments with frequencies greater than $20 \%$ were identified and removed by fragment frequency analysis. Lastly, only the size files with 30-200 fragments were exported for contig assembly with the FPC program.

\section{BAC contig assembly}

Physical map contig assembly was performed with the FPC program v9.4 (http://www.agcol.arizona.edu/software/fpc) [46]. The FPC parameters were adjusted for the method of HICF as described by Nelson et al. and $\mathrm{Xu}$ et al. [42,48]. The standard deviations of the size distributions of two vector fragments (157.4 bp and $369.6 \mathrm{bp}$ ) in 300 randomly chosen BAC clones were calculated to obtain the $95 \%$ confidence intervals. The tolerance value was set to 4 according to the result of these calculations, and the gel length was 
set at 18,000 bp in consideration of the size range (from $50 \mathrm{bp}$ to $500 \mathrm{bp}$ ). Because the average insert size was $155 \mathrm{~kb}$ and the average valid bands were 80.2 per clone, the average size per band was estimated to be $1,933 \mathrm{bp}$. The "Best of" function was set to 100 builds. Then a series of preliminary contig assemblies to determine the optimal cutoff value, which would limit the number of $\mathrm{Q}$ clones and avoid a great decrease of genome coverage, was performed on the whole data with different cutoff values ranging from $1 \mathrm{e}-20$ to $1 \mathrm{e}-75$. Based on the results of these tests, a very low initial cutoff value of 1e-60 was chosen to carry out the initial contig assembly. Contigs with more than $10 \% \mathrm{Q}$ clones in initial assembly were broken up by the "DQer" function with a step size of 9. Then, the stringency was decreased at nine successively lower cutoff from $1 \mathrm{e}-60$ to $1 \mathrm{e}-$ 15. At each step, the "Ends to Ends" auto merge function was used to merge the resulting contigs with a minimum of one (from $1 \mathrm{e}-60$ to $1 \mathrm{e}-45$ ) or two (from $1 \mathrm{e}-40$ to $1 \mathrm{e}-15$ ) matching ends and the "keyset to FPC" function was used to merge the singletons to the end of the contigs, respectively.

\section{Physical map quality assessment}

Physical map quality assessment was performed using PCR assays as described by $\mathrm{Xu}$ et al. [45]. The contigs to be assessed were selected randomly, but the even distribution of the clones end-sequenced in contig was also taken into consideration so as to develop enough and appropriate PCR primers. All clones in the selected contigs were inoculated from the stocking 384-well plates. BAC DNA was extracted using the alkaline lysis method as described above. All of the primers used in the assays are listed in the table of Additional file 2. Twenty-five $\mu \mathrm{l}$ of PCR solution contained $1 \times$ PCR buffer, $160 \mu \mathrm{mol} / \mathrm{L}$ of each dNTPs, $0.12 \mu \mathrm{mol} / \mathrm{L}$ forward primer, $0.12 \mu \mathrm{mol} / \mathrm{L}$ reverse primer, $1 \mathrm{mmol} / \mathrm{L} \mathrm{MgCl}_{2}$, $1 \mathrm{U}$ of Taq DNA polymerase (Fermentas, Glen Burnie, Maryland, USA) and about 10 ng BAC DNA. Reactions were conducted on all or some of the BAC clones in a specific contig under the following conditions: initial denaturation at $95^{\circ} \mathrm{C}$ for $5 \mathrm{~min}$; then 35 cycles of $95^{\circ} \mathrm{C}$ for $30 \mathrm{~s}, 55^{\circ} \mathrm{C}$ for $30 \mathrm{~s}$ and $72^{\circ} \mathrm{C}$ for $30 \mathrm{~s}$; and final extension at $72^{\circ} \mathrm{C}$ for $5 \mathrm{~min}$. The PCR products were then subjected to electrophoresis on $1.2 \%$ agarose gel. The BAC clones that produced specific bands with proper sizes were considered to have true overlap with the clones used to develop primers.

\section{Additional files}

Additional file 1: The observed changes in the numbers of $Q$ clones singletons, and contigs versus cutoffs. A series of preliminary assemblies of half-smooth tongue sole physical map were performed on the whole data with different cutoff values ranging from $1 \mathrm{e}-20$ to $1 \mathrm{e}-75$. A cutoff value of 1 e- 60 was chosen for the initial automatic assembly.

Additional file 2: List of primers used for assessing the half-smooth tongue sole physical map.
Competing interests

The authors declare that they have no competing interests.

\section{Authors' contributions}

JZ worked on clone culture, data process, map assembly and drafted the manuscript. CS participated in the study design, library manipulation and provided end sequences. LZ worked on DNA extraction and purification. KL participated in enzyme digestion and fluorescent labeling. FG participated in data collection. ZD participated in contig validation. PX guided the experiment and provided assistance for data analysis and manuscript preparation. SC conceived, designed and supervised the entire study. All authors read and approved the final manuscript.

\section{Acknowledgements}

This project was supported by grants from National Natural Science Foundation of China (31130057), National Hi-Tech R\&D Program of China (863 Program) (2012AA092203, 2012AA10A403-2), and Taishan Scholar Project Fund of Shandong of China.

\section{Author details}

${ }^{1}$ Yellow Sea Fisheries Research Institute, Chinese Academy of Fishery Sciences, Qingdao 266071, China. ${ }^{2}$ College of Fisheries and Life Science, Shanghai Ocean University, Shanghai 201306, China. ${ }^{3}$ College of Animal Science, Xinjiang Agricultural University, Urumqi 830052, China. ${ }^{4}$ The Centre for Applied Aquatic Genomics, Chinese Academy of Fishery Sciences, Beijing 100141, China.

Received: 15 November 2013 Accepted: 10 March 2014

Published: 20 March 2014

\section{References}

1. Li SZ, Wang SM: In Fauna Sinica, Osteichthyes Pleuronectiformes. Edited by Editorial Committee of Fauna Sinica, Academia Sinica. Beijing: Science Press; 1995:98.

2. $\quad$ Meng QW, Su JX, Miao XZ: Fish Taxonomy. Beijing: China Agriculture Press; 1995:979-981.

3. Jiang YW, Wan RJ, Chen RS, Liu YL, Chen GW, Zhang SB, Fan DD, Fang $H$ : Studies on technique of artificial fry rearing of Cynoglossus semilaevis Günther in Bohai Sea. Mar Fish Res 1993, 14:25-33.

4. Chen SL, Li J, Deng SP, Tian YS, Wang QY, Zhuang ZM, Shan ZX, Xu JY: Isolation of female-specific AFLP markers and molecular identification of genetic sex in Half-smooth tongue sole (Cynoglossus semilaevis). Mar Biotechnol 2007, 9:273-280.

5. Z Zhuang ZM, Wu D, Zhang SC, Pang QX, Wang CL, Wan RJ: G-banding patterns of the chromosomes of tonguefish Cynoglossus semilaevis Günther, 1873. J Appl Ichthyol 2006, 22:437-440.

6. Chen SL, Tian YS, Yang JF, Shao CW, Ji XS, Zhai JM, Liao XL, Zhuang ZM, Su $P Z, X u$ JY, Sha ZX, Wu PF, Wang N: Artificial gynogenesis and sex determination in Half-smooth tongue sole (Cynoglossus semilaevis). Mar Biotechnol 2009, 11:243-251.

7. Shao CW, Wu PF, Wang XL, Tian YS, Chen SL: Comparison of chromosome preparation methods for the different developmental stages of the Half-smooth tongue sole, Cynoglossus Semilaevis. Micron 2010, 41:47-50.

8. Liao XL, Shao CW, Tian YS, Chen SL: Polymorphic dinucleotide microsatellites in tongue sole (Cynoglossus semilaevis). Mol Ecol Notes 2007, 7:1147-1149.

9. Liu YG, Sun XQ, Gao H, Liu LX: Microsatellite markers from an expressed sequence tag library of Half-smooth tongue sole (Cynoglossus semilaevis) and their application in other related fish species. Mol Ecol Notes 2007, 7:1242-1244.

10. Liu YG, Bao BL, Liu LX, Wang L, Lin H: Isolation and characterization of polymorphic microsatellite loci from RAPD product in Half-smooth tongue sole (Cynoglossus semilaevis) and a test of cross-species amplification. Mol Ecol Resources 2008, 8:202-204.

11. Sha Z, Wang S, Zhuang Z, Wang Q, Wang Q, Li P, Ding H, Wang N, Liu Z, Chen S: Generation and analysis of 10000 ESTs from the Half-smooth tongue sole Cynoglossus semilaevis and identification of microsatellite and SNP markers. J Fish Biol 2010, 76:1190-1204.

12. Deng SP, Chen SL: CDNA cloning, tissue, embryos and larvae expression analysis of Sox10 in Half-smooth tongue-sole, Cynoglossus semilaevis. Mar Genomics 2008, 1:109-114. 
13. Deng SP, Chen SL, Xu JY, Liu BW: Molecular cloning, characterization and expression analysis of gonadal P450 aromatase in the half-smooth tongue-sole, Cynoglossus semilaevis. Aquaculture 2009, 287:211-218.

14. Deng SP, Chen SL: Molecular cloning, characterization and RT-PCR expression analysis of Dmrt1a from half-smooth tongue-sole, Cynoglossus semilaevis. J Fish Sci China 2008, 15:577-584.

15. Shao CW, Chen SL, Scheuring CF, Xu JY, Sha ZX, Dong XL, Zhang HB: Construction of two BAC libraries from Half-smooth tongue sole Cynoglossus semilaevis and identification of clones containing candidate sex-determination genes. Mar Biotechnol 2010, 12:558-568.

16. Liao XL, Ma HY, Xu GB, Shao CW, Tian YS, Ji XS, Yang JF, Chen SL: Construction of a genetic linkage map and mapping of a female-specific DNA marker in Half-smooth tongue sole (Cynoglossus semilaevis). Marine Biotechnol 2009, 11:699-709.

17. Song WT, Li YZ, Zhao YW, Liu Y, Niu YZ, Pang RY, Miao GD, Liao XL, Shao CW, Gao FT, Chen SL: Construction of a high-density microsatellite genetic linkage map and mapping of sexual and growth-related traits in Half-smooth tongue sole (Cynoglossus semilaevis). PloS One 2012, 7:e52097.

18. Chen S, Zhang G, Shao C, Huang Q, Liu G, Zhang P, Song W, An N, Chalopin D, Volff JN, Hong Y, Li Q, Sha Z, Zhou H, Xie M, Yu Q, Liu Y, Xiang H, Wang N, Wu K, Yang C, Zhou Q, Liao X, Yang L, Hu Q, Zhang J, Meng L, Jin $L$, Tian $Y$, Lian J, et al: Whole-genome sequence of a flatfish provides insights into ZW sex chromosome evolution and adaptation to benthic life. Nat Genet 2014, 46:253-260.

19. Shao C, Li Q, Chen S, Zhang P, Lian J, Hu Q, Sun B, Jin L, Liu S, Wang Z, Zhao H, Jin Z, Liang Z, Li Y, Zheng Q, Zhang Y, Wang J, Zhang G: Epigenetic modification and inheritance in sexual reversal of fish. Genome Res 2014. doi:10.1101/gr.162172.113.

20. Lander ES, Linton LM, Birren B, Nusbaum C, Zody MC, Baldwin J, Devon K, Dewar K, Doyle M, FitzHugh W, Funke R, Gage D, Harris K, Heaford A, Howland J, Kann L, Lehoczky J, LeVine R, McEwan P, McKernan K, Meldrim J, Mesirov JP, Miranda C, Morris W, Naylor J, Raymond C, Rosetti M, Santos R, Sheridan A, Sougnez C, et al: Initial sequencing and analysis of the human genome. Nature 2001, 409:860-921.

21. Li RQ, Fan W, Tian G, Zhu HM, He L, Cai J, Huang QF, Cai QL, Li B, Bai YQ, Zhang ZH, Zhang YP, Wang W, Li J, Wei FW, Li H, Jian M, Li JW, Zhang ZL, Nielsen R, Li DW, Gu WJ, Yang ZT, Xuan ZL, Ryder OA, Leung FCC, Zhou Y, Cao JJ, Sun $X, F u Y G$, et al: The sequence and de novo assembly of the giant panda genome. Nature 2010, 463:311-317.

22. Warren RL, Varabei D, Platt D, Huang XQ, Messina D, Yang SP, Kronstad JW Krzywinski M, Warren WC, Wallis JW, Hillier LDW, Chinwalla AT, Schein JE, Siddiqui AS, Marra MA, Wilson RK, Jones SJM: Physical map-assisted wholegenome shotgun sequence assemblies. Genome Res 2006, 16:768-775.

23. Lewin HA, Larkin DM, Pontius J, O'Brien SJ: Every genome sequence needs a good map. Genome Res 2009, 19:1925-1928.

24. Lorenz S, Brenna-Hansen S, Moen T, Roseth A, Davidson WS, Omholt SW, Lien S: BAC-based upgrading and physical integration of a genetic SNP map in Atlantic salmon. Anim Genet 2010, 41:48-54.

25. Palti Y, Genet C, Luo MC, Charlet A, Gao GT, Hu YQ, Castaño-Sánchez C, Tabet-Canale K, Krieg F, Yao JB, Vallejo RL, Rexroad CE: A first generation integrated map of the rainbow trout genome. BMC Genomics 2011, 12:180.

26. Zhao L, Zhang Y, Ji PF, Zhang XF, Zhao ZX, Hou GY, Huo LH, Liu GM, Li C, $X u$ P, Sun XW: A dense genetic linkage map for common carp and its integration with a BAC-based physical map. PloS One 2013, 8:e63928.

27. García-Cegarra A, Merlo MA, Ponce M, Portela-Bens S, Cross I, Manchado M, Rebordinos L: A Preliminary Genetic Map in Solea senegalensis (Pleuronectiformes, Soleidae) Using BAC-FISH and Next-Generation Sequencing. Cytogenet Genome Res 2013, 141:227-240.

28. Zhang XJ, Scheurin CF, Zhang MP, Dong JJ, Zhang Y, Huang JJ, Lee MK, Abbo S, Sherman A, Shtienberg D, Chen WD, Muehlbauer F, Zhang HB: A BAC/BIBACbased physical map of chickpea, Cicer arietinum L. BMC Genomics 2010, 11:501.

29. Paux E, Sourdille P, Salse J, Saintenac C, Choulet F, Leroy P, Korol A, Michalak M, Kianian S, Spielmeyer W, et al: A physical map of the 1gigabase bread wheat chromosome 3B. Science 2008, 322:101-104

30. Zhang Y, Liu SK, Lu JG, Jiang YL, Gao XY, Ninwichian P, Li C, Waldbieser G, Liu $\mathrm{ZJ}$ : Comparative genomic analysis of catfish linkage group 8 reveals two homologous chromosomes in zebrafish and other teleosts with extensive inter-chromosomal rearrangements. BMC Genomics 2013, 14:387.

31. Marra MA, Kucaba TA, Dietrich NL, Green ED, Brownstein B, Wilson RK, Ken MM, LaDeana WH, John DM, Waterston RH: High throughput fingerprint analysis of large-insert clones. Genome Res 1997, 7:1072-1084.
32. Gregory SG, Howell GR, Bentley DR: Genome mapping by fluorescent fingerprinting. Genome Res 1997, 7:1162-1168.

33. Luo MC, Thomas C, You FM, Hsiao J, Ouyang S, Buell CR, Malandro M, McGuire PE, Anderson OD, Dvorak J: High-throughput fingerprinting of bacterial artificial chromosomes using the snapshot labeling kit and sizing of restriction fragments by capillary electrophoresis. Genomics 2003, 82:378-389.

34. McPherson JD, Marra M, Hillier LD, Waterston RH, Chinwalla A, Wallis J, Sekhon M, Wylie K, Mardis ER, Wilson RK, Fulton R, Kucaba TA, Wagner-McPherson C, Barbazuk WB, Gregory SG, Humphray SJ, French L, Evans RS, Bethel G, Whittaker A, Holden JL, McCann OT, Scott CE, Bentley DR, Schuler G, Chen HC, Jang W, Green ED, Idol JR, Maduro WB, et al: A physical map of the human genome. Nature 2001, 409:934-941.

35. Wu CC, Sun SK, Nimmakayala P, Santos FA, Meksem K, Springman R, Ding $\mathrm{KJ}$, Lightfoot DA, Zhang HB: A BAC-and BIBAC-based physical map of the soybean genome. Genome Res 2004, 14:319-326.

36. Mun JH, Kwon SJ, Yang TJ, Kim HS, Choi BS, Baek S, Kim JS, Jin M, Kim JA, Lim MH, Lee SI, Kim HI, Kim H, Lim YP, Park BS: The first generation of a BAC-based physical map of Brassica rapa. BMC Genomics 2008, 9:280.

37. Kingsley DM, Zhu BL, Osoegawa K, De Jong PJ, Schein J, Marra M, Peichel C, Amemiya C, Schluter D, Balabhadra S, Friedlander B, Cha YM, Dickson M, Grimwood J, Schmutz J, Talbot WS, Myers R: New genomic tools for molecular studies of evolutionary change in threespine sticklebacks. Behaviour 2004, 141:11-12

38. Ng SHS, Artieri CG, Bosdet IE, Chiu R, Danzmann RG, Davidson WS, Fergusonc MM, Fjell CD, Hoyheim B, Jones SJM, Jonge PJD, Koopf BF, Krzywinski MI, Lubieniecki K, Marra MA, Mitchell LA, Mathewsonb C, Osoegawa K, Parisottoa SE, Phillips RB, Rise ML, Schalburgf KRV, Scheinb JE, Shinb H, Siddiqui A, Thorsend J, Wye N, Yang G, Zhu BL: A physical map of the genome of Atlantic salmon, Salmo salar. Genomics 2005, 86:396-404.

39. Katagiri T, Kidd C, Tomasino E, Davis JT, Wishon C, Stern JE, Carleton KL, Howe AE, Kocher TD: A BAC-based physical map of the Nile tilapia genome. BMC Genomics 2005, 6:89.

40. Zhang XJ, Zhao C, Huang C, Duan H, Huan P, Liu CZ, Zhang XY, Zhang Y, Li $\mathrm{FH}$, Zhang HB, Xiang JH: A BAC-based physical map of Zhikong scallop (Chlamys farreri Jones et Preston). PloS One 2011, 6:e27612.

41. Quiniou SM, Waldbieser GC, Duke MV: A first generation BAC-based physical map of the channel catfish genome. BMC Genomics 2007, 8:40.

42. Xu P, Wang SL, Liu L, Thorsen J, Kucuktas H, Liu ZJ: A BAC-based physical map of the channel catfish genome. Genomics 2007, 90:380-388.

43. Palti Y, Luo MC, Hu YQ, Genet C, You FM, Vallejo RL, Thorgaard GH, Wheeler PA, Rexroad CE: A first generation BAC-based physical map of the rainbow trout genome. BMC Genomics 2009, 10:462

44. Xia JH, Feng F, Lin G, Wang CM, Yue GH: A first generation BAC-based physical map of the Asian seabass (Lates calcarifer). PLoS One 2010, 5:e11974.

45. Xu P, Wang J, Wang JT, Cui RZ, Li Y, Zhao ZX, Ji PF, Zhang Y, Li JT, Sun XW: Generation of the first BAC-based physical map of the common carp genome. BMC Genomics 2011, 12:537.

46. Soderlund C, Longden I, Mott R: FPC: a system for building contigs from restriction fingerprinted clones. Comput App/ Biosci 1997, 13:523-535.

47. Nelson WM, Dvorak J, Luo MC, Messing J, Wing RA, Soderlund C: Efficacy of clone fingerprinting methodologies. Genomics 2007, 89:160-165.

48. Nelson WM, Soderlund C: Software for restriction fragment physical maps In The Handbook of Genome Mapping: Genetic and Physical Mapping. Edited by Meksem K, Kahl G. Weinheim: Wiley-VCH; 2005:285-306.

49. Nelson WM, Bharti AK, Butler E, Wei FS, Fuks G, Kim H, Wing RA, Messing J, Soderlund C: Whole-genome validation of high-information-content fingerprinting. Plant Physiol 2005, 139:27-38.

50. Sambrook J, Russell DW: Molecular Cloning: A Laboratory Manual. 3rd edition. Cold Spring Harbor: Cold Spring Harbor Laboratory Press; 2001:1-68.

\section{doi:10.1186/1471-2164-15-215}

Cite this article as: Zhang et al:: A first generation BAC-based physical map of the half-smooth tongue sole (Cynoglossus semilaevis) genome. BMC Genomics 2014 15:215. 